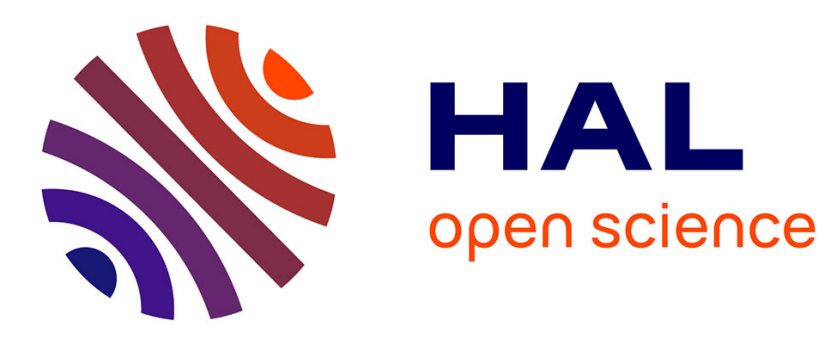

\title{
Multi-physical characterization of micro-contact materials for MEMS switches
}

\author{
Adrien Broué, J. Dhennin, Pierre-Louis Charvet, Patrick Pons, N. Ben Jemaa, \\ Fabio Coccetti, Robert Plana
}

\section{- To cite this version:}

Adrien Broué, J. Dhennin, Pierre-Louis Charvet, Patrick Pons, N. Ben Jemaa, et al.. Multi-physical characterization of micro-contact materials for MEMS switches. 56th IEEE Holm Conference on Electrical Contacts, Oct 2010, Charleston, United States. 10 p. hal-00670153

\section{HAL Id: hal-00670153 \\ https://hal.science/hal-00670153}

Submitted on 14 Feb 2012

HAL is a multi-disciplinary open access archive for the deposit and dissemination of scientific research documents, whether they are published or not. The documents may come from teaching and research institutions in France or abroad, or from public or private research centers.
L'archive ouverte pluridisciplinaire HAL, est destinée au dépôt et à la diffusion de documents scientifiques de niveau recherche, publiés ou non, émanant des établissements d'enseignement et de recherche français ou étrangers, des laboratoires publics ou privés. 


\title{
Multi-physical characterization of micro-contact materials for MEMS switches
}

\author{
A. Broue ${ }^{1-3-4}$, J. Dhennin ${ }^{1}$, P.-L. Charvet ${ }^{2}$, P. Pons ${ }^{3-4}$, N. Ben Jemaa ${ }^{5}$, P. Heeb ${ }^{6}$, F. Coccetti ${ }^{1}$, R. Plana ${ }^{3-4}$ \\ ${ }^{1}$ NOVAMEMS, ${ }^{2}$ CEA-LETI, MINATEC, ${ }^{3}$ CNRS ; LAAS ; 7 avenue du colonel Roche, F-31077 Toulouse (France), ${ }^{4}$ Université \\ de Toulouse ; UPS, INSA, INP, ISAE ; LAAS ; F-31077 Toulouse (France), ${ }^{5}$ IPR-Université de Rennes, ${ }^{6}$ NTB
}

\begin{abstract}
A systematic comparison between several pairs of contact materials based on an innovative methodology early developed at NOVA MEMS is hereby presented. The technique exploits a commercial nanoindenter coupled with electrical measurements, and test vehicles specially designed in order to investigate the underlying physics driving the surface-related failure modes. The study provides a comprehensive understanding of micro-contact behavior with respect to the impact of low- to medium levels of electrical current. The decrease of the contact resistance, when the contact force increases, is measured for contact pairs of soft material (Au/Au contact), harder materials $(R u / R u$ and $R h / R h$ contacts) and mixed configuration ( $\mathrm{Au} / \mathrm{Ru}$ and $\mathrm{Au} / \mathrm{Ni}$ contacts). The contact temperatures have been calculated and compared to the theoretical values of softening temperature for each couple of contact materials. This threshold temperature is reached for gold, ruthenium and rhodium material, with different levels of current intensity. In spite of that, no softening behavior has been observed for mixed contact at the theoretical softening temperature of both materials. Hence, considering the sensitivity to power handling and the related failure mechanisms, namely the contact adhesion, the enhanced resilience of the bimetallic contacts $\mathrm{Au} / \mathrm{Ru}$ and $\mathrm{Au} / \mathrm{Ni}$ was demonstrated. Finally focusing on the temperature distribution around the hottest levels on the surface contact interface, these results have been theoretically investigated.
\end{abstract}

Keywords-microcontact; MEMS; micro-switch; contact temperature; contact materials; adhesion; creep.

\section{INTRODUCTION}

Micro-switches are one of the most promising fields of MNT (Micro- and Nano- Technology) for a variety of commercial and military applications. Metal contact RF MEMS switches have indeed demonstrated excellent performances in terms of low-power consumption, low onstate impedance, high off-state impedance, and excellent linearity [1]. However, the high-reliability level required for further integration of these technologies in complex systems is currently a major challenge. Indeed, the TRL (Technology Readiness Level) of these devices hardly managed to increase in the past few years. Particularly, studying the behavior of the electrical micro contact remains difficult due to the small sizes at stake. The key issue is the electromechanical behavior of the materials used at the contact interface. In particular the contact pressure and the corresponding temperature have to be controlled precisely, knowing that these two parameters are interdependent. In addition, more complete data for electrical and thermo-mechanical properties of contacts made with thinfilm metallization are also required to support the miniaturization of electrical contacts in multichip systems, three-dimensional (3-D) systems [2] and wafer-level testing probe cards [3][4].

Works on FEM structural-contact analysis were reported at Memswave 2009 where temperature was studied at the contact interface [5]. Fortini presented a nanoscale comparison of $\mathrm{Au}$ and $\mathrm{Ru}$ contact behavior using molecular dynamics simulation [6]. Experimental characterizations using a nanoindenter [7], piezo actuator [8] and atomic force microscope (AFM) [9] were published by researchers, to investigate the behavior of $\mathrm{Au}$ and Au-Ni alloys as contact materials by mechanical actuation with increasing force. To our knowledge, micro-scale heating effects are not fully understood, especially when a layer of impurity is present on the contact surfaces. However these phenomena are essential to design and optimize a contact such to withstand a given power level before reaching the critical temperature values for the used material [5]. The analysis of the impact at low to medium power level on $\mathrm{Au} / \mathrm{Au}, \mathrm{Ru} / \mathrm{Ru}, \mathrm{Rh} / \mathrm{Rh}, \mathrm{Au} / \mathrm{Ru}$ and $\mathrm{Au} / \mathrm{Ni}$ based RF MEMS contacts differs from previous works as the contact temperature study is based on experimental results. This represents a first important step toward the definition of a useful database for several contact materials.

Hence, a new set-up was developed for the characterization of contact materials used in micro- switches. In a previous paper by the same author, presented the study of the $\mathrm{Au} / \mathrm{Au}$, $\mathrm{Ru} / \mathrm{Ru}$ and $\mathrm{Au} / \mathrm{Ru}$ contact resistance, comparing the stability with respect to an increased level of current [10]. This paper is an extension of [11] with a focus on contact asperity, heating and contact adhesion over rising level of current flowing through the contact and for several contact materials endowed with different electro-mechanical properties.

The work presented in this paper proposes a method for comparing the behavior of five couples of contact materials. It is organized as follows. The subsection 2 is an overview of the background theory related to the micro-contact physics. In subsection 3, the set-up and the capability of this methodology are described. Experimental results are presented in subsection 4. Discussed and theoretical analysis of these results follow in subsection 5, while the summary and conclusions are closing the paper with subsection 6 .

\section{BACKGROUND THEORY}

The electromechanical behavior of the contacting surfaces during switching depends on several mechanical and electrical parameters. The stability of the contact surfaces through switching cycles must be insured: the electrical, topological and mechanical properties have to be maintained over the entire device lifetime. 


\section{A. Contact resistance models}

The micro-contact physically differs from the macrocontact due to the influence of surface roughness and the smaller contact force available in micro switches. Only high points on each surface come in contact, and the effective contact area, named asperities or a-spots, is largely smaller than the apparent one. The way the electrons are transported through electrical connections (ballistic, quasi-ballistic or ohmic transport) needs to be determined in order to evaluate the resistance of contact.

\section{- Ohmic contact}

If considering a single circular spot of contact, "Ohmic contact" means that the contact size $a$, that is to say its radius, is at least one order of magnitude higher than the mean free path $l_{e}$ of the electrons in the material $\left(l_{e}<<a\right)$. In this case the Ohm's law can be applied everywhere. The measured contact resistance is then essentially dominated by a diffuse scattering mechanism, and is given by the Holm resistance formula. This electrical resistance is directly linked to the constriction of current lines between the two contacts. It causes a local increase of the current density and tends to increase the electrical potential drop between the two sides of the asperity. The expression of this constriction resistance is:

$$
R_{\text {Holm }}=\frac{\rho}{2 a}
$$

where $\rho$ is the resistivity of the contact material. It's necessary to keep in mind that, generally, the current flows by multiple asperities. The easiest approach consists in considering that the whole conductance $1 / R_{\text {eff }}$ is the sum of conductances $1 / R_{n}$ of the multiple contact spots with varying sizes (no interaction between the spots).

$$
\frac{1}{R_{e f f}}=\sum_{n} \frac{1}{R_{n}}
$$

This expression is a first approximation. More complex models can be used to find an accurate approximation [12].

- Ballistic contact

This model must be used if the mean free path of the electrons, $l_{e}$, is high compared with the radius of contact. The conduction of the contact spot is then dominated by Sharvin's resistance [14]. The electrons flow ballistically through the two parts of the contact without being scattered. This means that these electrons collide mostly elastically within the constriction. When $l_{e}>>a$, the local form of the Ohm's law cannot be used in the neighbor belt of the asperities. Sharvin's resistance is a semi-classical approximation for electron with ballistic transport behavior:

$$
R_{S}=\frac{4 \rho K}{3 \pi a}
$$

where $a$ is this time the effective radius of contact (for $N$ asperities, $a_{e f f}=N . a$ ). $K$ stands for the Knudsen's number given by $K=\frac{l_{e}}{a}$.

\section{- $\quad$ Mixed conduction}

If the two precedent models are not applicable, for example $l \sim a$, a mixed one has to be used in this middle situation. Wexler has given a solution of the Boltzmann equation using variational principle to maintain the continuity of the conduction behaviour between the diffusive and the ballistic domain. This Wexler's resistance $R_{W e x l e r}$ results in a simple interpolation between the Sharvin's and Holm's resistances, respectively $R_{\text {Sharvin }}$ and $R_{\text {Holm }}$ :

$$
R_{\text {Wexler }}=\Gamma(K) R_{\text {Holm }}+R_{\text {Sharvin }}
$$

with $\Gamma(K)$ a slowly varying Gamma function. Mikrajuddin et al. [14] derived a well behaved Gamma function:

$$
\Gamma(K) \approx \frac{2}{\pi} \int_{0}^{\infty} e^{-K x} \operatorname{Sinc}(x) d x
$$

To simplify the model, the effects of contaminant films have been neglected in all this calculus.

\section{B. Asperity deformation model}

When the two contact surfaces collide with each other, the asperities of each contact could have three deformation modes: elastic, elastic-plastic and plastic, depending on the level of stress applied to the materials. During the first contact establishment between the two surfaces, the stress applied on the high points of the asperities is generally higher than the yield stress of the contact material. This is due to a necessary roughness adaptation of the surfaces (burn-in). Thus the deformation of the contact asperities is considered to be predominantly plastic. The contact area and the contact load can be linked to the radius of the contact spot a using Abbott and Firestone's plastic contact model [12]:

$$
a=\sqrt{\frac{A_{C}}{\pi}}=\sqrt{\frac{F_{C}}{H \pi}}
$$

Where $A c$ is the contact area, $F_{C}$ the contact force and $H$ the Meyer hardness of the softer material. This leads the stress to reduce towards the Yield point after several actuations, where the behavior becomes closer to a domain of perfect-elastic or elastic-plastic transition. Thus, only perfect-plastic behavior will be first considerate, by applying Abbott and Firestone's plastic contact model.

Any time-dependant thermo-mechanical deformations can be taken into account using creep formalism [13]:

$$
\dot{\varepsilon}=A \sigma^{p} \exp \left(-\frac{Q_{C}}{k T}\right)
$$

where $\dot{\varepsilon}$ is the strain rate, A a parameter related to the material properties and the creep mechanism, $\sigma$ the stress, $\mathrm{p}$ the creep exponent, $Q_{c}$ the activation energy for creep, $T$ the absolute temperature and $k$ is the Boltzmann constant.

\section{Contact temperature model}

Heating of the contact spots is extremely localized when the current flows through the contact: the device level remains at room temperature but softening or melting temperatures can be reached on the asperities [14]. The highest contact spot 
temperature $T_{C}$ has been expressed by Kohlrauch as a function of the contact voltage $V_{c}$ for a ohmic contact [12]:

$$
T_{C}=\sqrt{\frac{V_{c}^{2}}{4 L}+T_{0}^{2}}
$$

Where $L=2.45 \times 10^{-8} \mathrm{~W} . \Omega / \mathrm{K}^{2}$ is the Lorentz constant and $T_{0}$ the ambient temperature. Eq. (8) is obtained from the Wiedemann-Franz law for a conductor heated by the current produced by the voltage $V_{C}$ between two arbitrary isotherms with the temperature $T_{0}$ : the assumption is made that the thermal and electric currents obey similar laws thus with symmetric contacts the generated heat flows in the same path as the electric current. The resistivity is also dependant from the temperature as:

$$
\rho_{T_{C}}=\rho_{0}\left(1+\alpha T_{C}\right)
$$

Where $\rho_{T c}$ and $\rho_{0}$ are respectively the resistivities at the temperature $T_{C}$ and at the room temperature $T_{0}, T_{C}$ the maximum contact temperature and $\alpha$ the temperature coefficient.

\section{Reliability of micro-contacts}

The reliability of the switch depends on its ability to withstand some degradations occurring at the contact interface.

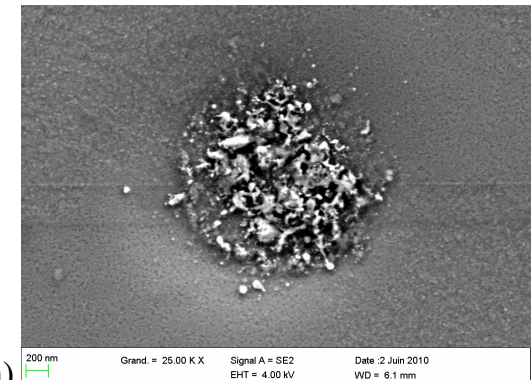

a)

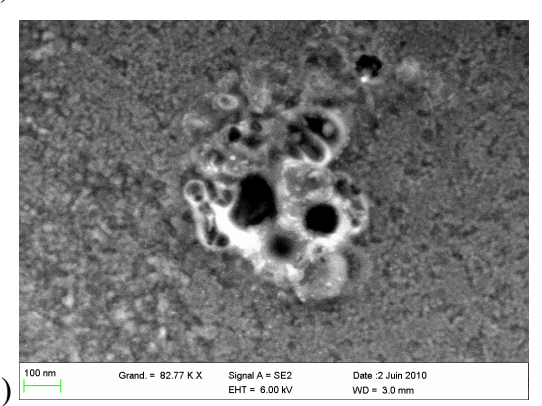

Figure 1: SEM pictures showing contact damages caused by high temperatures at the contact interface after cycling a) on a plan shape b) on a spherical shape $\left(F c=150 \mu \mathrm{N} /(\mathrm{Ic})_{\mathrm{MAX}}=100 \mathrm{~mA}\right)$

Three types of root causes can be studied: the mechanical (cold welding, wear, strain hardening), electrical (arcing, hot welding, annealing) and chemical ones (formation of insulating films at the extreme surface), all inducing modifications of the topological, mechanical and electrical properties of the contact. The contact temperature is a first order parameter determining the reliability of the switch. It has to be studied to reach a stable and low contact resistance. For example, the plastic deformation of the asperities proceeds more rapidly when the softening temperature $T_{s}$ is reached [6]. Thus the effective contact area increases inducing a drop of the contact resistance. However the softening of the metal at the asperities of contact reduces also the strain hardening of the a-spots and could accelerate the wear of the contact as well as material transfer, or contaminant built-up on contact surfaces. Therefore, the understanding of potential failure mechanisms can be made easier with the setup presented in this paper.

\section{E. Contact material focus}

Performances of electrical contacts in MEMS switches are strongly linked with the materials used. Its mechanical and electrical properties will govern the evolution of the contact resistance when the load is applied. The best compromise between mechanical and electrical performances has to be found in order to reach reliable operations. The material must have good electrical conductivity to avoid losses, high melting point to handle power, appropriate hardness to avoid stiction, and chemical inertness to avoid oxidation [8]. This information can be partly found in the literature, but it does not replace a direct quantitative test of the performances of each material, thanks to the setup presented in next subsection.

\section{METHODOLOGY}

\section{A. Description of the experimental set-up}

Advanced characterization of the contact properties requires high control of the load applied to the contact, of the displacement of the moving part, and of the electrical properties of this contact.

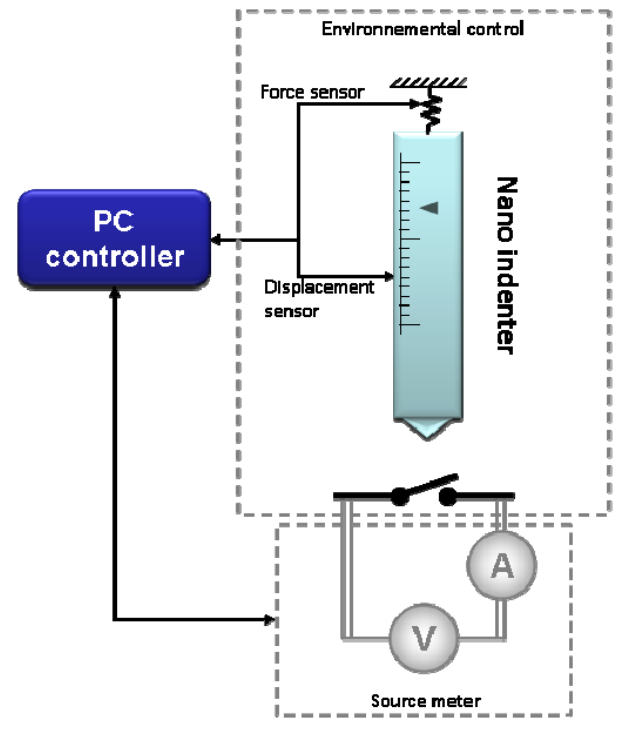

Figure 2: Principle of the electrical test performed with a nanoindentation

$$
\text { tip }
$$

These conditions can be reached using a nanoindenter coupled with a high-resolution source meter. The spherical diamond tip acts as a mechanical actuator, which applies a punctual load on the free-standing electrode mimicking the switch action at the contact interface. Previous works described the set-up and showed the relevance of such an approach to simulate a distributed actuation pressure [15]. A schematic view of the set-up can be seen on Figure 1. A Keithley 2400 
source meter is used in order to carry out the four-point DC contact resistance measurement to avoid the path resistance term (similar technique as Holm's cross-rod experiment). The test structures are reported and micro bonded on a PCB (Printed Circuit Board).

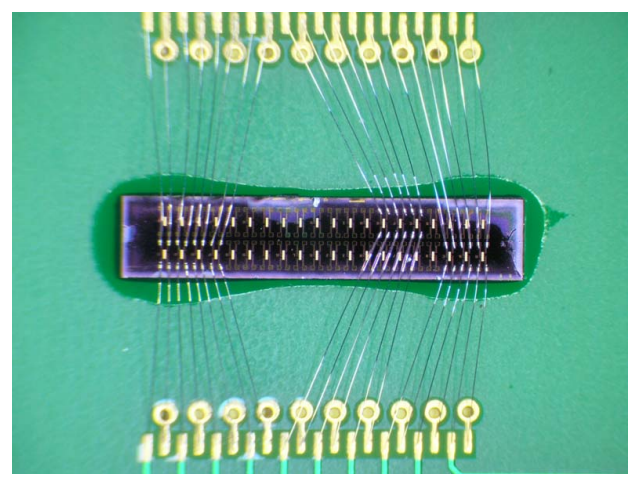

Figure 3: Test vehicles on PCB

The entire set-up is placed in a constant N2-flushed chamber $(>97 \% \mathrm{~N} 2, \mathrm{RH}<5 \%)$ to reduce the environmental contamination of the contact surfaces. The table 1 reports input and output parameters for beam bending experiment.

\begin{tabular}{|c|c|}
\hline Source Modes & Switching Modes \\
\hline - Current source & $\begin{array}{l}\text { Hot switching } \\
\text { Cold switching } \\
\text { Mechanical switching }\end{array}$ \\
\hline - Voltage source & $\begin{array}{l}\text { Hot switching } \\
\text { Cold switching } \\
\text { Mechanical switching }\end{array}$ \\
\hline Input Parameters & Range \\
\hline $\begin{array}{l}\text { - } \quad \text { Current level }(I C) \\
\text { - } \quad \text { Maximum load applied }\left(L_{\max }\right) \\
\text { - } \quad \text { Compliance voltage }(V c) \\
\text { - } \quad \text { Holding plateau at load max } t_{\text {hold }} \\
\end{array}$ & $\begin{array}{l}0.01 \text { to } 100 \mathrm{~mA} \\
1 \mu \mathrm{N} \text { to } 6 \mathrm{mN} \\
10^{-5} \text { to } 40 \mathrm{~V} \\
0 \text { to several min }\end{array}$ \\
\hline Environment & Dry nitrogen $(<5 \% \mathrm{RH})$ \\
\hline \multicolumn{2}{|c|}{ Outputs } \\
\hline $\begin{array}{l}\text { Voltage Drop (Vc) or current } \\
\text { drop (Ic) [depending on the source } \\
\text { mode] }\end{array}$ & - Contact stiffness $(K)$ \\
\hline - Tip Displacement $(d)$ & - Contact resistance $(R c)$ \\
\hline
\end{tabular}

\section{B. Test vehicle description}

Specific test vehicles have been designed in order to allow an efficient extraction of characteristic curves and make possible the comparison between different contact shapes or materials. As illustrated in Figure 4, the microfabricated devices are composed of a bridge suspended over a contact line. Thanks to a true four-points system and the specific design, the only contact resistance is measured, being the resistance of the remaining structure, lines and bridge patterned on the substrate automatically removed. This method for measuring contact resistance is the same as the one used in crossed rod design of Holm [9]. A $3 \mu \mathrm{m} \times 3 \mu \mathrm{m}$ bump is processed underneath the bridge. Four contact materials are tested (cf. table 2): first gold, which is the most popular material for electrical contact because of its high bulk conductivity, low contact resistance even at small contact forces, its high oxidation resistance, its low propensity to form alien surface films [16] and its compatibility with MEMS fabrication methods.

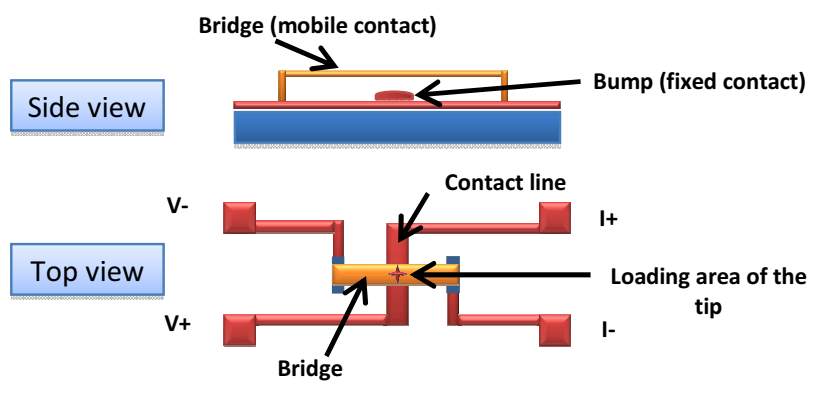

Figure 4: Schematic of the test structures

However, gold is a soft material subject to large modifications of the contact surface while switching cycles occur. Furthermore, gold is prone to contact wear and stiction, which affect the contact performance.

\begin{tabular}{|c|c|c|c|c|}
\hline Contact materials & $\mathrm{Au}$ & $\mathbf{R u}$ & $\mathbf{R h}$ & $\mathbf{N i}$ \\
\hline $\begin{array}{l}\text { Thickness of the outer } \\
\text { coatings }(\mu \mathrm{m})\end{array}$ & $\begin{array}{c}\text { Bridge: } \\
3 \mu \mathrm{m} \\
\text { Bump: } \\
1 \mu \mathrm{m}\end{array}$ & $\begin{array}{l}\text { Bridge: } \\
0.1 \mu \mathrm{m} \\
\text { Bump: } \\
0.1 \mu \mathrm{m}\end{array}$ & $\begin{array}{c}\text { Bridge: } \\
0.05 \mu \mathrm{m} \\
\text { Bump: } \\
0.1 \mu \mathrm{m}\end{array}$ & $\begin{array}{l}\text { Bridge: } \\
2 \mu \mathrm{m}\end{array}$ \\
\hline $\begin{array}{l}\text { Electrical resistivity at } \\
20^{\circ} \mathrm{C}(\mu \Omega . \mathrm{cm})\end{array}$ & 2.3 & 7.6 & 4.51 & 6.84 \\
\hline $\begin{array}{l}\text { Softening temperature } \\
\qquad\left({ }^{\circ} \mathrm{C}\right)\end{array}$ & $\begin{array}{c}\sim 100^{\circ} \mathrm{C} \\
{[14]}\end{array}$ & $\begin{array}{c}\sim 430^{\circ} \mathrm{C} \\
{[12]}\end{array}$ & $x$ & $\sim 520^{\circ} \mathrm{C}[12]$ \\
\hline $\begin{array}{l}\text { Melting temperature } \\
\left({ }^{\circ} \mathrm{C}\right)[13]\end{array}$ & $1063^{\circ} \mathrm{C}$ & $2450^{\circ} \mathrm{C}$ & $1964^{\circ} \mathrm{C}[19]$ & $1453^{\circ} \mathrm{C}[12]$ \\
\hline $\begin{array}{l}\text { Boiling temperature } \\
\left({ }^{\circ} \mathrm{C}\right)[13]\end{array}$ & $2966^{\circ} \mathrm{C}$ & $4900^{\circ} \mathrm{C}$ & $3695^{\circ} \mathrm{C}[19]$ & $2837^{\circ} \mathrm{C}[12]$ \\
\hline $\begin{array}{c}\text { Estimated } \\
\text { hardness(GPa) [13] }\end{array}$ & $\sim 1.6$ & 10.1 & $\sim 25[20]$ & $13,7[12]$ \\
\hline
\end{tabular}

This is the reason why new contact metals such as $\mathrm{Ru}, \mathrm{Rh}$ and $\mathrm{Ni}$, have to be introduced. These are much harder than pure $\mathrm{Au}$ or any $\mathrm{Au}$ alloy. They may provide better resistance stability in spite of a higher bulk resistivity [17]. On the other hand, ruthenium and rhodium are typical frictional polymerforming metals, they tend to adsorb organic vapor from air and form a contaminating film [18]. Nevertheless, the introduction of these contact metal candidates with higher melting point gives the opportunity to investigate their behavior under large current levels.
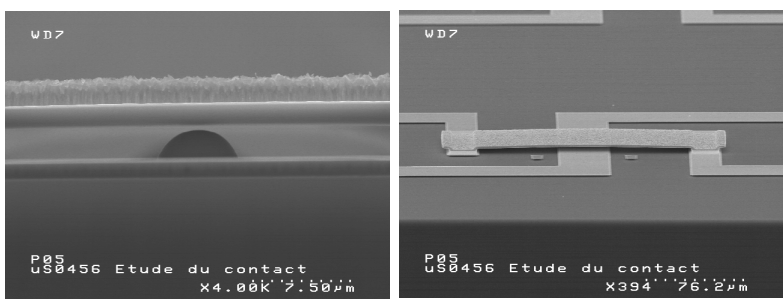

Figure 5: SEM images of a test vehicle

Five kinds of test structures with different contact metals are used for this study: $\mathrm{Au} / \mathrm{Au}, \mathrm{Ru} / \mathrm{Ru}, \mathrm{Au} / \mathrm{Ru}, \mathrm{Rh} / \mathrm{Rh}$ and $\mathrm{Au} / \mathrm{Ni}$. They have been successfully fabricated at LETI (Au, $\mathrm{Ru}, \mathrm{Ni}$ ) and NTB (Rh contact), and stored in dry $\mathrm{N}_{2}$ to slow down any environmental contamination of the contact surfaces. In spite of that gradual contamination accumulation still 
occurred due to the device transfer between the different laboratories. The underlying electrodes are gold PVD (physical vapour deposition / thickness of $1 \mu \mathrm{m})$, ruthenium PVD (thickness of $0.1 \mu \mathrm{m}$ ) and rodium PVD (thickness of $0.1 \mu \mathrm{m}$ ) and the mobile contacts are gold ECD (electro chemical deposition / thickness of $3 \mu \mathrm{m}$ ), nickel ECD (thickness of $2 \mu \mathrm{m}$ ), rhodium PVD (thickness of $0.05 \mu \mathrm{m}$ ), and ruthenium PVD (thickness of $0.1 \mu \mathrm{m}$ ) according to the test structures.

\section{EXPERIMENTAL RESULTS}

\section{A. Contact force versus contact resistance}

First, we tested the response of the contact resistance with increasing contact force by loading and unloading 11 times the bridge with an increased current level each cycle (from $1 \mathrm{~mA}$ to $100 \mathrm{~mA}$.) When the contact is established between two metallic electrodes, the effective contact area is very low. Only the higher points of the electrodes are in contact. The contact area is then very low and the contact resistance is high and unstable. At a certain minimum force, depending on the material under investigation, a significant reduction of the resistance occurs because considerable plastic deformation takes place, causing rupture of undesired films at the contact interface. At higher forces, the contact remains stable and the resistance decreases slightly with further increasing of the force until a saturated regime is reached [21].
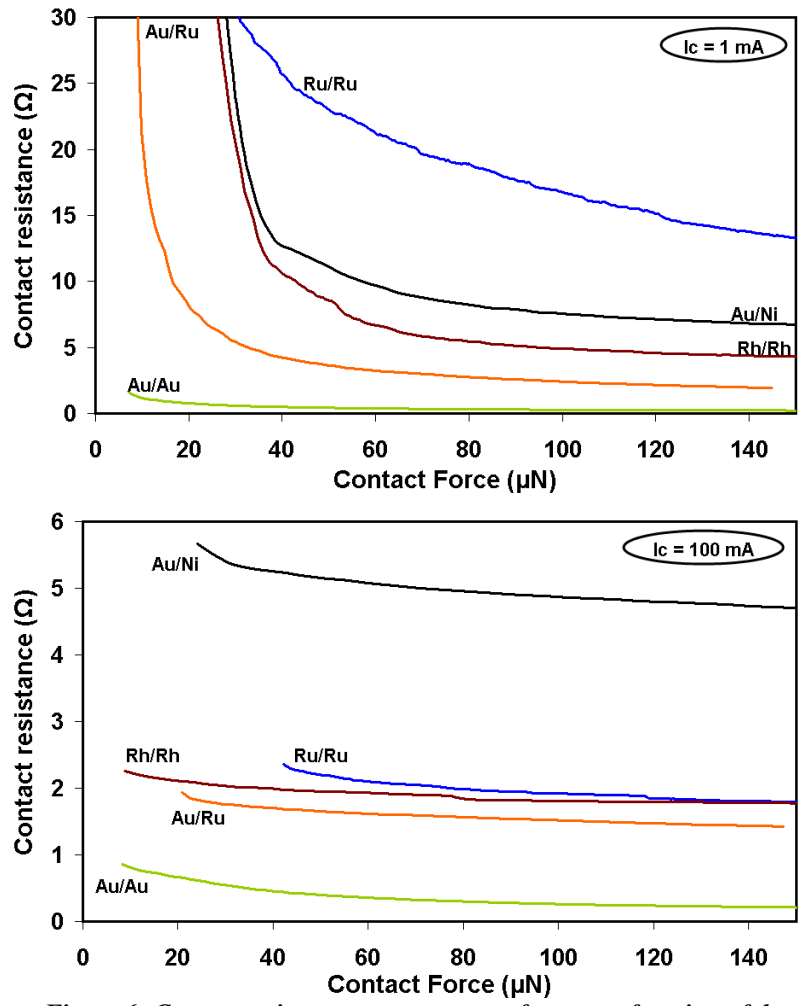

Figure 6: Contact resistance versus contact force as a function of the current flowing through the contact for $A u / R u, A u / A u, R u / R u, R h / R h$ and Au/Ni contacts at $1 \mathrm{~mA}$ and $100 \mathrm{~mA}$

Figure 6 shows the contact resistance of for $\mathrm{Au} / \mathrm{Ru}, \mathrm{Au} / \mathrm{Au}$, $\mathrm{Ru} / \mathrm{Ru}, \mathrm{Rh} / \mathrm{Rh}$ and $\mathrm{Au} / \mathrm{Ni}$ contacts as a function of the measured contact force with a contact current of $1 \mathrm{~mA}$ and
$100 \mathrm{~mA}$. The results are investigated in terms of comparison of the contact resistance level. In this experiment, $\mathrm{Au} / \mathrm{Au}$ contact shows the more stable and the lowest contact resistance beyond contact force about $40 \mu \mathrm{N}$ from $1 \mathrm{~mA}\left(\mathrm{R}_{\mathrm{c}}=0.49 \Omega\right)$ to $100 \mathrm{~mA}$ $\left(R_{c}=0.45 \Omega\right)$. Gold is a soft material easily deformed with a large contact area. These results on gold contacts have to be taken carefully in account because gold contact surfaces have already been flattened by previous tests. On the contrary, $\mathrm{Ru} / \mathrm{Ru}$ contact shows high contact resistance above 13 ohms with $140 \mu \mathrm{N}$ of contact force at $1 \mathrm{~mA}$. The low conductivity and high hardness of the ruthenium explain this result. The contact asperities are more easily flattened at $100 \mathrm{~mA}$ where the contact resistance value is one order of magnitude lower $(\mathrm{Rc}=1.70 \Omega)$. It is also observed that $\mathrm{Rh} / \mathrm{Rh}$ contact reaches a lower contact resistance at $140 \mu \mathrm{N}$ compared to the $\mathrm{Ru} / \mathrm{Ru}$ contact at $1 \mathrm{~mA}$. This result could be attributed to the low resistivity of the rhodium compared to the ruthenium. This in spite of the larger mechanical hardness value of the rhodium. Yet, the value of the contact resistance at $100 \mathrm{~mA}$ is very similar to the $\mathrm{Ru} / \mathrm{Ru}$ contact. The high temperature at this current level softens the contact metal and leads to an increased contact area by plastic deformation. The higher hardness of rhodium minimized the plastic deformation due to softening compared to ruthenium. These hard metals would probably provide better performances with higher levels of current and adequate contact force.

$\mathrm{The} \mathrm{Au} / \mathrm{Ru}$ bimetallic contact is relatively stable at the maximum contact load. From $1 \mathrm{~mA}$ to $100 \mathrm{~mA}$, the contact resistance at $145 \mu \mathrm{N}$ decreases from $1.9 \Omega$ to $1.4 \Omega$. The a-spots of $\mathrm{Au}$ on the contact surface are more easily deformed due to the lower hardness compared to $\mathrm{Ru}$. The behavior of the $\mathrm{Au} / \mathrm{Ru}$ contact seems nearer to a very soft material rather than being in between a soft and a hard material. This confirms that in an asymmetric contact made of a soft and a hard material is the former to dictate the overall behavior. Our assumption is that the asperities of the softer material are much more deformed by a hard material surface. The results on $\mathrm{Au} / \mathrm{Ni}$ contact are quiet surprising because of the high level of the contact resistance, which is consistently higher than the expected one for $1 \mathrm{~mA}$ to $100 \mathrm{~mA}$. It is suspected that the Ni part of the contact collected a large layer of contaminants on the contact surface because of a long period of hazardous storage. Previous work has also shown that the adsorbed film layers are less mobile at low temperatures and can be mechanically removed from the contacting area through cycling or under sufficiently high current [13]. However, the resistance of the $\mathrm{Au} / \mathrm{Ni}$ contact is roughly stable from $1 \mathrm{~mA}$ to $100 \mathrm{~mA}$ in comparaison with monometallic contacts (except for gold contact).

Special efforts have to be made to well understand these first results. In general, the results on $\mathrm{Au} / \mathrm{Ru}$ provided an attractive trade-off between low contact resistance and handling of relatively high power as will be shown in the next session.

\section{B. Contact heating focus}

Five sets of experimental results are presented in this paper to investigate the impact of increased contact current on asperity heating at ambient temperature. To further examine the heating effect on contact resistance, the study is focused on the contact temperature when the maximum contact load is reached at $150 \mu \mathrm{N}$ by gradually loading and unloading the bridge with 
an increased current level at each cycle. The methodology consists in measuring the contact voltage while applying the current through the asperities. The contact temperature is then calculated by means of the contact voltage measured across the contact (Eq 8). By this way the behavior of the temperature across the contact can be observed while the level of current is increasing.

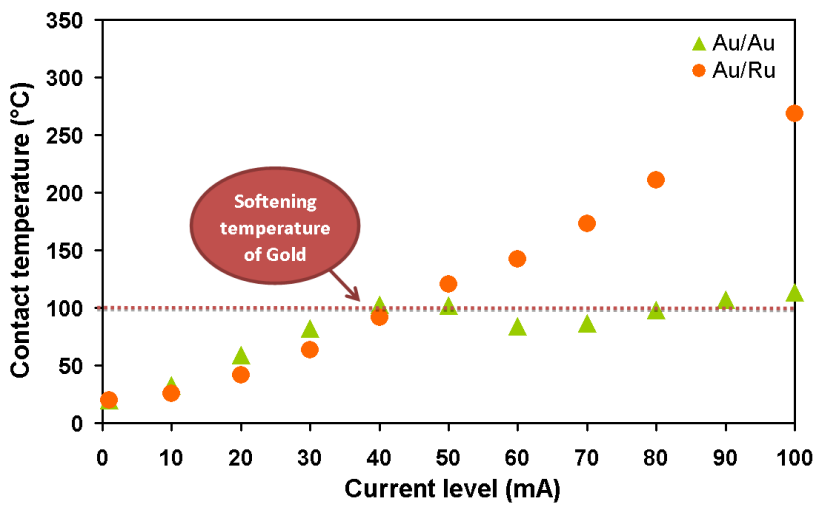

Figure 7: Contact temperature versus the contact current for $\mathrm{Au} / \mathrm{Au}$ and $\mathrm{Au} / \mathrm{Ru}$ contacts at a contact force of $150 \mu \mathrm{N}$

The published softening temperature for gold contact is $\sim 100^{\circ} \mathrm{C}$, corresponding to a contact voltage of $70-80 \mathrm{mV}$ for contact near room temperature [12]. For $\mathrm{Au} / \mathrm{Au}$ contact, the current is increased until reaching the softening temperature, around 40mA (Figure 7). Then, the contact resistance continues to decrease keeping the contact temperature roughly constant. The contact temperature increases with a constant slope from $1 \mathrm{~mA}$ to $40 \mathrm{~mA}$. The potential drop across the contact remains almost constant between $65 \mathrm{mV}$ and $75 \mathrm{mV}$ (from $80^{\circ} \mathrm{C}$ to $120^{\circ} \mathrm{C}$ ).

The same behavior is partially observed for other symmetrical contact $\mathrm{Ru} / \mathrm{Ru}$ (Figure 8).

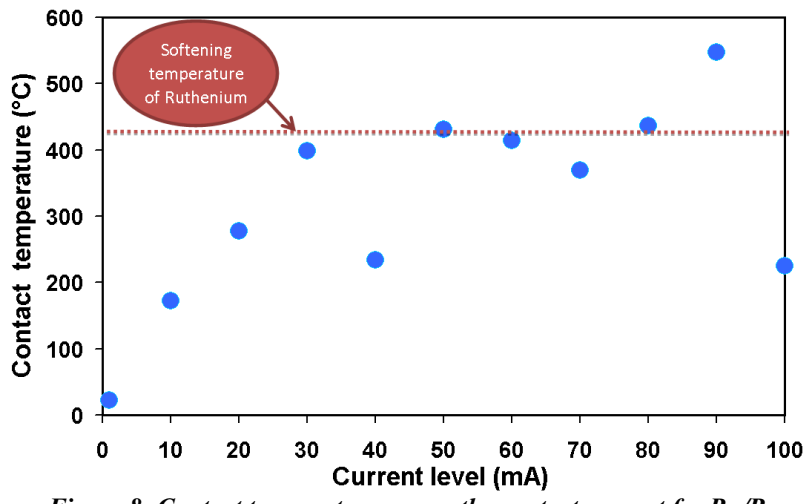

Figure 8: Contact temperature versus the contact current for $R u / R u$ contacts at a contact force of $150 \mu \mathrm{N}$

The published softening temperature for ruthenium contact is $\sim 430^{\circ} \mathrm{C}$, corresponding to a contact voltage of $200 \mathrm{mV}$ and contact near room temperature [22]. As pointed out previously, when the softening temperature is reached, the contact temperature does not depend strongly on contact current at high current levels. Beyond this value, the contact temperature is unstable even though it seems to oscillate around this softening temperature.
Furthermore, similar results were observed for the $\mathrm{Rh} / \mathrm{Rh}$ contact (Figure 9).

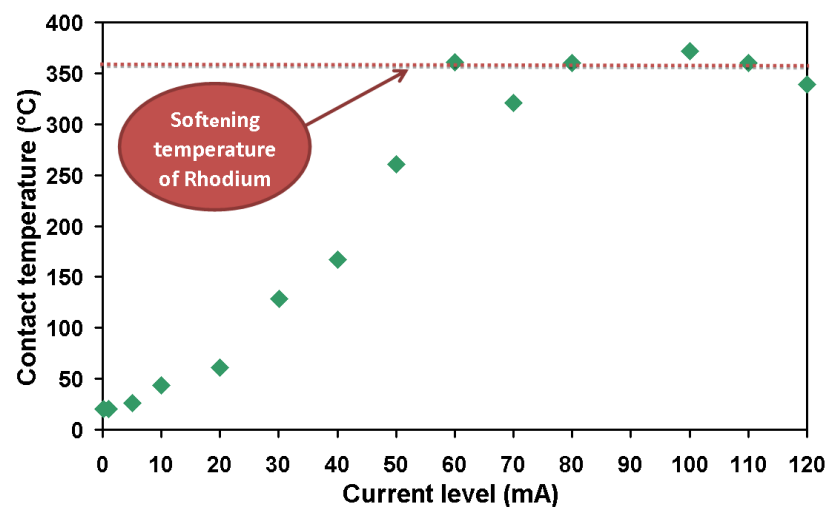

Figure 9: Contact temperature versus the contact current for $R h / R h$ contacts at a contact force of $150 \mu \mathrm{N}$

To our knowledge, the softening temperature of rhodium is still unknown, and has not been reported yet in the literature. This pronounced leveling of the potential occurs in the same manner than for $\mathrm{Au} / \mathrm{Au}$ and $\mathrm{Ru} / \mathrm{Ru}$ contacts. This result suggests that the softening temperature of rhodium is around $360^{\circ} \mathrm{C}$.

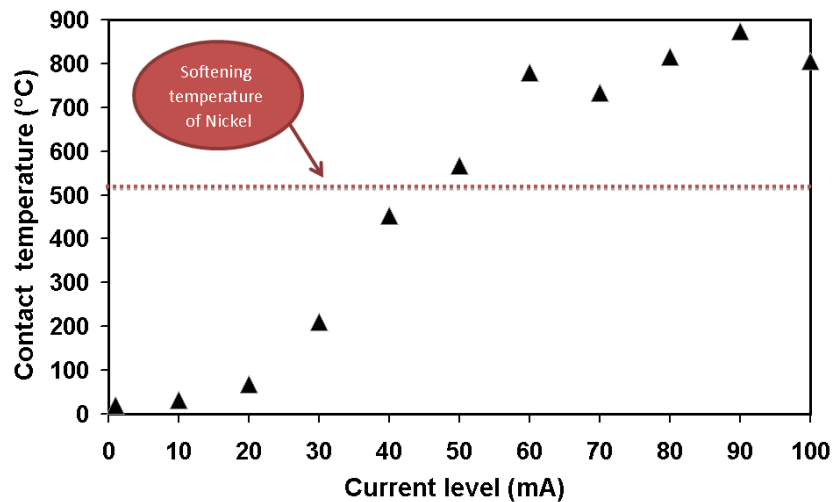

Figure 10: Contact temperature versus the contact current for $\mathrm{Au} / \mathrm{Ni}$ contacts at a contact force of $150 \mu N$

On the other hand, the behavior for the bimetallic contacts $\mathrm{Au} / \mathrm{Ni}$ and $\mathrm{Au} / \mathrm{Ru}$ defers from the two others. As shown in Figure 7 , the contact temperature increases with the current level without reaching a maximum. And the leveling of the potentials across the $\mathrm{Au} / \mathrm{Ni}$ contact is observed, but for contact temperatures largely higher than the nickel or the gold softening temperature (cf. Figure 10). Interestingly thermomechanical deformations of the contact areas are different than the previous contacts. In asymmetrical contacts, the temperature distribution within the contact constriction is not comparable to the one in symmetrical contacts: as the conductivity of both materials are different, thermoelectric effects appear.

\section{Thermo-mechanical deformation of the contact asperities for Au/Au contact}

Figure 11 shows the evolution of the contact resistance during the holding plateau at a constant contact force of $150 \mu \mathrm{N}$. The time-dependent electrical resistance of a closed 
gold contact is observed while the current level is swept from $1 \mathrm{~mA}$ to $100 \mathrm{~mA}$ each 20 seconds. The contact temperature is calculated after each current sweep.

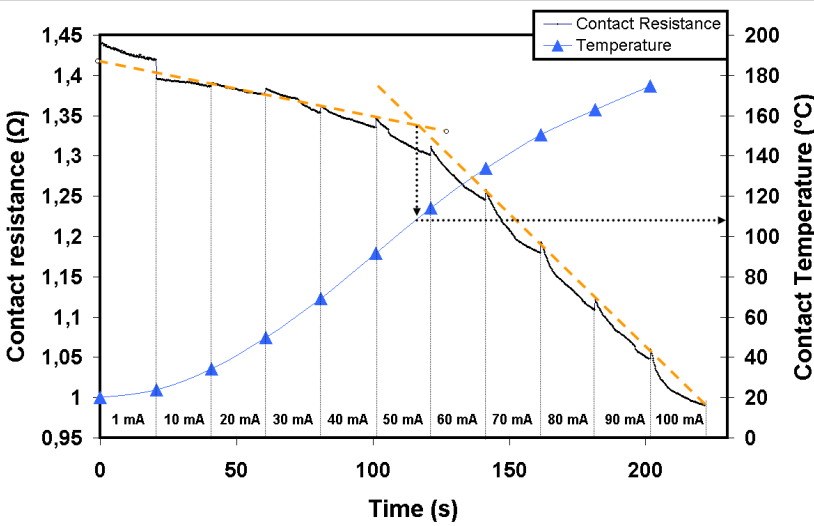

Figure 11: Time dependence of contact resistance by increasing the contact current for Au/Au contacts at a contact force of $150 \mu \mathrm{N}$. The contact temperature is also reported.

The results can be roughly divided into two phases. A first one within a current level from $1 \mathrm{~mA}$ to $40 \mathrm{~mA}$ characterized by a moderate constant value of creep, which increase significantly over the remaining measured current range. From $60 \mathrm{~mA}$, a constant decrease of the contact resistance for each current level is observed. The variation in the contact resistance drop appears at $50 \mathrm{~mA}$, with a contact temperature between $91{ }^{\circ} \mathrm{C}$ and $114^{\circ} \mathrm{C}$. Hence, it was concluded that thermal softening occurred during testing. The results suggest that contact temperature contributes to the flattening of the contact asperities due to the lowering of the local hardness occurring at this temperature. An increased contact surface is formed by the plastic deformation induced by the contact pressure during the holding part.

An AFM scan is used to study the roughness of the contact bump of the $\mathrm{Au} / \mathrm{Au}$ contact in different phases. The first picture shows the bump of an pristine contact. The second picture is the AFM image of the bump coming from the same run but after being as previously described. It clearly shows that the top of the bump has been flattened due to the plastic deformation of the a-spots. The measurements highlight that the rms roughness of the top of the contact bump $\left(1 \mu \mathrm{m}^{2}\right)$ decrease from $21.7 \mathrm{~nm}$ to $11.3 \mathrm{~nm}$.

\section{Adhesive tests}

As previously said, micro-switches require a reliable opening of the closed contact. In our experiments, some contact exhibits a pronounced adherence during the unloading of the bridge. This set-up provides the exceeding force to reopen the contact with a continuously increasing tensile force. The force sensor of the nanoindenter measures the adhesion during the discontinuing of the mechanical and electrical contact. Moreover, the evolution in the pull-off force while increasing the current is tracked in order to show variations on the adhesion versus the contact temperature. These tests are done in a quasi-cold switching mode $\left(I=1 \mu \mathrm{A}\right.$ and $V_{c}=$ $0.05 \mathrm{mV}$ ) and with a relative humidity below $5 \%$ to guarantee low moisture content conditions.
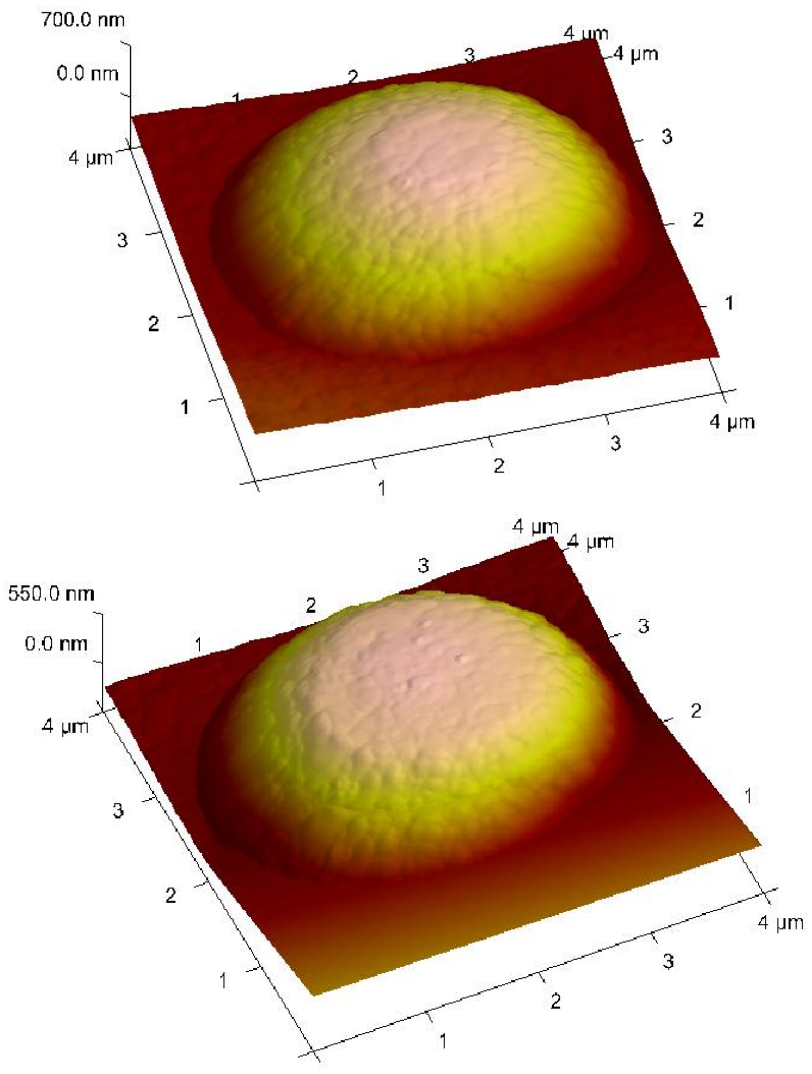

Figure 12: 3D-image of a tested bump(a) and an untested one (b) taken by AFM. (scan range $4 \times 4 \mu \mathrm{m}$ ).

Results on $\mathrm{Au} / \mathrm{Au}$ contact show that contact begin to adhere with a really low current. The increase of the current level does not affect the contact adhesion. These results can be explained by the low contact resistance $(<0.2 \Omega)$ for the $\mathrm{Au} / \mathrm{Au}$ contacts generated by a large contact area at $150 \mu \mathrm{N}$. This yields an increase of the metallic bond and leads to a higher adhesion between the contact surfaces. For the $\mathrm{Ru} / \mathrm{Ru}$ case, the behavior of the contact parts differs from the gold one. Adhesion is quasi nonexistent under $30 \mathrm{~mA}$. Ruthenium based contacts have a higher hardness leading to less plastic yield during loading and hence, smaller adhesion during unloading. Beyond this value, adherence increases as the result of the metal softening around the contact. For the $\mathrm{Rh} / \mathrm{Rh}$ contact, the pull-off force increases with the contact current. In spite of this a limiting adherence voltage, as described by Holm [12], could not be observed.

$\mathrm{Au} / \mathrm{Ru}$ contact shows low adherence without high evolution of the pull-off force. The experimental data for the $\mathrm{Au} / \mathrm{Ni}$ contact is very similar to the $\mathrm{Au} / \mathrm{Ru}$ contact. The evolution of the pull-off force with increasing current is really different for bimetallic contacts as this kind of contacts prevents the adherence between the contact parts. If the part with the higher softening temperature is not softened at the contact interface, the conditions for adherence are probably not reached. More extensive exploration of the adherence conditions have to be done in order to explain why the adhesion seems to become smaller for the bimetallic contacts. 

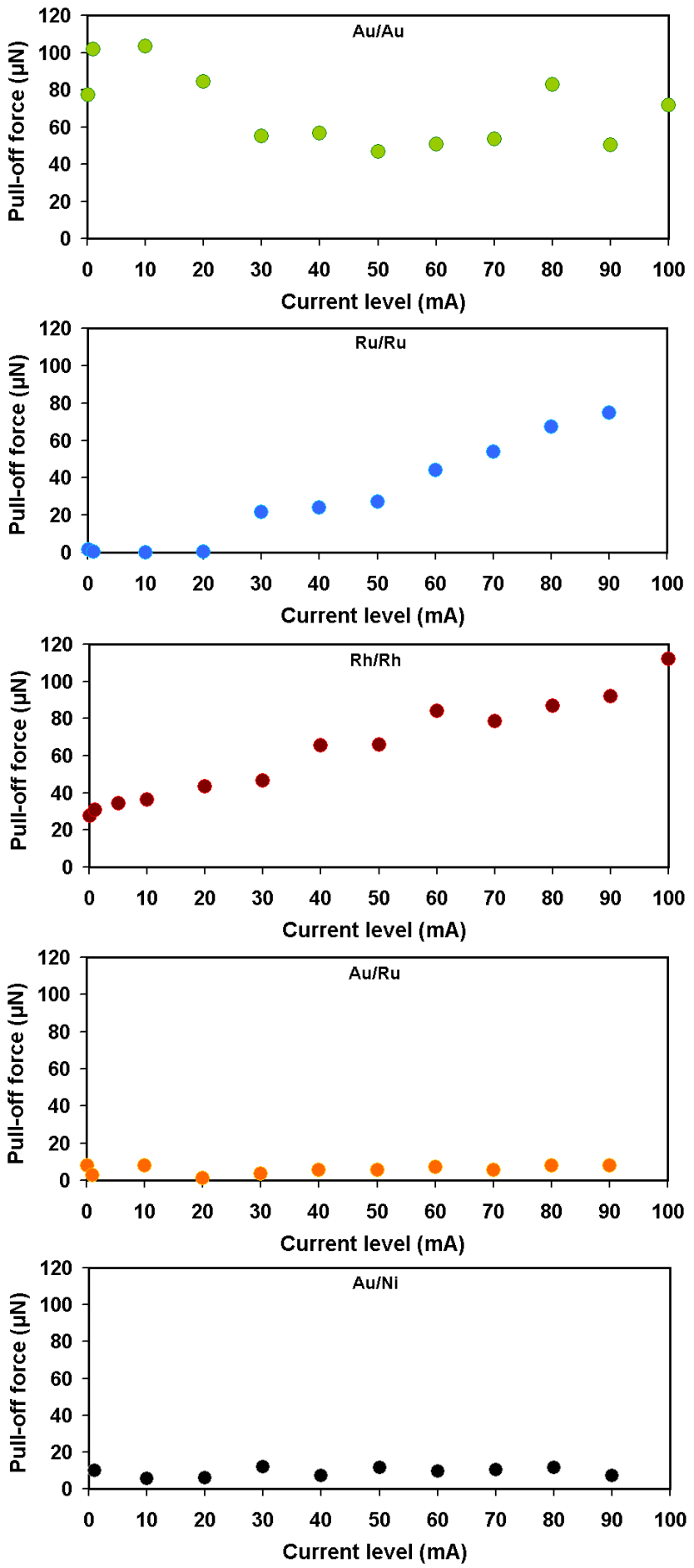

Figure 13: Pull-off force versus contact current

\section{DiscusSION OF RESUltS}

The comparison between measured contact resistance data and predictions made using Holm's model and Wexler's model for plastically deformed a-spot is shown in Figure 14 for $\mathrm{Au} / \mathrm{Au}$ contact at $1 \mathrm{~mA}$. It is seen that the simulated contact resistance of the both models are different at low applied pressures. The models converge at higher contact forces due to the $100 \%$ diffusive electron transport predicted by the Wexler model. The difference between the experimental and modeled data is most likely attributed to contaminants on the gold contact surface because the effects of contaminant films have been neglected in all the contact resistance model. This result confirms the presence of a film at the interface of the electrical junction which affects the electron transport through the contact.

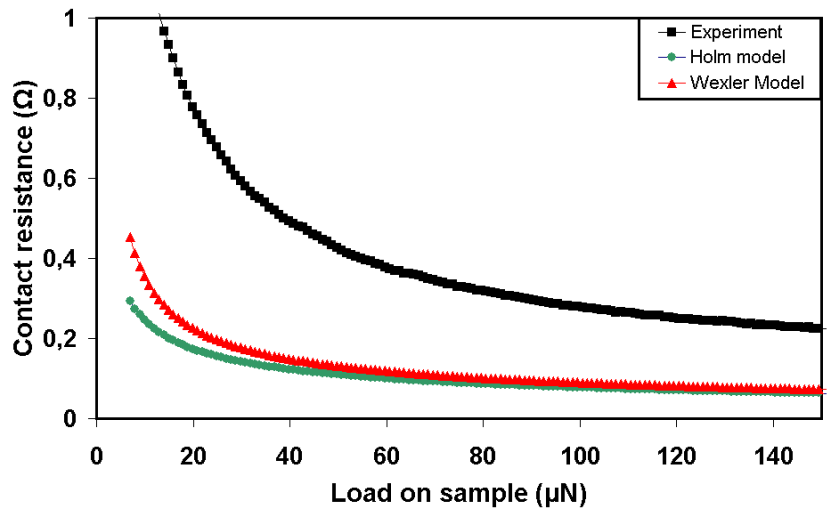

Figure 14: Experimental and analytical electrical contact resistance versus the load applied on the Au/Au contact at $1 \mathrm{~mA}$

As seen previously, heating of the contact is extremely localized, resulting, at the contact interface, in temperatures hundred of degrees higher than in the surrounding material. Contact softening is commonly linked to the annealing of the material and to the reduction of the contact hardness. As the current through the contact spot increases, joule heating softens the asperities allowing the contacts to sink together [12]. This leads to a thermally induced reduction of the contact resistance.

Nevertheless, the contact area generated by this procedure is determined probably more by fracture of the insulating films than by the vanishing of the strain hardening. The constant DC electrical current has a sufficient magnitude to generate an elevated temperature in the contact spot. After the rise of the contact temperature, the softening temperature is reached as the sintering of the junction. These refractory particles are pressed onto the edges of the film free contact area or embedded in the metal contact surface as the two parts penetrate each other. In these conditions the contact resistance decreases due to thermal breakdown of insulating films.

In addition, the previous section pointed out the dissimilar behaviors of symmetrical and asymmetrical contact materials. For the symmetrical contacts, the potential across the contacts cannot really exceed the softening voltages at these current levels. On the contrary the asymmetrical contacts may withstand voltages beyond the softening level of the contact materials. The Figure 15.a provides a schematic view of the symmetric case (same material, Metal 1).

The assumption that the electrical and thermal currents flow in the same paths is always supported by the Wiedemann-Franz law [12]. $T_{0}$ is the bulk temperature in the both members of the contact. The highest temperature $T_{C}$ is localized at the extreme contact interface across which no heat flows for a monometallic contact. The temperature distribution is symmetric around the 
hottest contact spot precisely localized at the intersection between both parts of the contact. The Figure 15.b illustrates the temperature distribution at the contact constriction between two different metals (Metal 1 and Metal 2) with different conductivities $\left(\rho_{\text {metal2 }}>>\rho_{\text {metal1 }}\right)$ and mechanical hardnesses $\left(\mathrm{H}_{\text {metal2 }} \gg \mathrm{H}_{\text {metal1 }}\right)$ [12]. The temperature distribution around the hottest area at the contact interface has changed because of the different nature of the both contact parts. Thus there is a change in the average distance of the thermoelectric heat flow. The maximum temperature $T_{C}$ is located within the less conductive material at a distance $\Delta \mathrm{z}$ from the physical interface [12]. A simple model predicts the location of the maximum temperature in a bimetallic contact [23]:

$$
\frac{\Delta z}{a}=\left[\frac{\left(\rho_{2, m}+\rho_{1, m}\right)}{2 \rho_{2, m}}\right]\left(\frac{\Delta V}{V_{C}}\right)\left(\frac{\pi}{2 \sqrt{2}}\right)
$$

where $\Delta V$ is the potential drop between the physical interface and the plane of maximum temperature, $\rho_{l, m}$ and $\rho_{2, m}$ are the electrical resistivities of material 1 and 2 at the maximum temperature $T_{C}$.
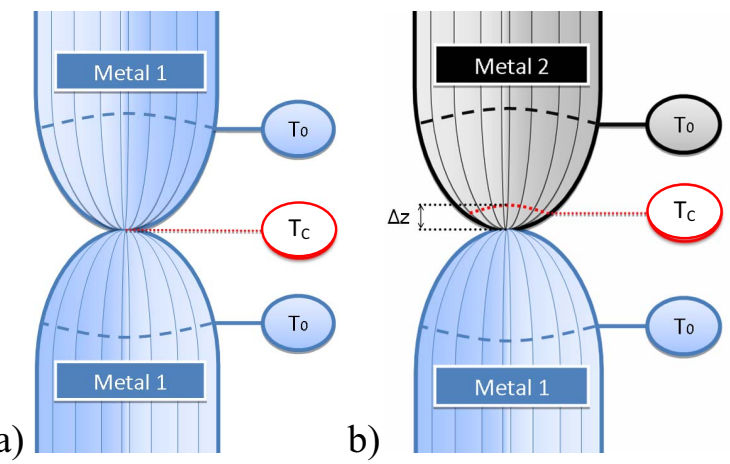

Figure 15: Temperature distribution a) in a symmetric constriction b) in the constriction of a contact between two metals Metal 1 and Metal 2 with different conductivities and hardness $\left(H_{\text {metal } 2}>>H_{\text {metal }}\right.$ and $\left.\rho_{\text {metal }}>>\rho_{\text {metall }}\right)$

Figure 16 depicts the location of the maximum temperature in the less conductive member of the bimetallic contact. The maximum temperature is always located within the thickness of the ruthenium and nickel layers $\left(\Delta z_{\mathrm{MAX}}=60 \mathrm{~nm}\right.$ for ruthenium and $\Delta \mathrm{z}_{\mathrm{MAX}}=220 \mathrm{~nm}$ for nickel). This deviation of the interfacial temperature has to be calculated for future works. As shown on Figure 16, the maximum temperature occurs in the vicinity of the contact interface. However this distance is not insignificant compared with the thickness of the outer coating layer, the scales of the a-spots and the topography of the contact surfaces. Thus the phenomenon observed in $\mathrm{Au} / \mathrm{Ru}$ and $\mathrm{Au} / \mathrm{Ni}$ contacts can be explained this way: the maximum temperatures calculated for these contacts are respectively located in the ruthenium and the nickel sides. Consequently, it has no influence on the contact asperities, and on the voltage and resistance measured. In addition, this explains the highest adhesion occurs between identical metals, whereas bimetallic combinations exhibit weaker adhesion [24]. The threshold temperature observed for $\mathrm{Au} / \mathrm{Ni}$ contact is probably a softening of the contact surfaces generated by the heat produced within the nickel member, and dissipated by conduction to the contact interface.
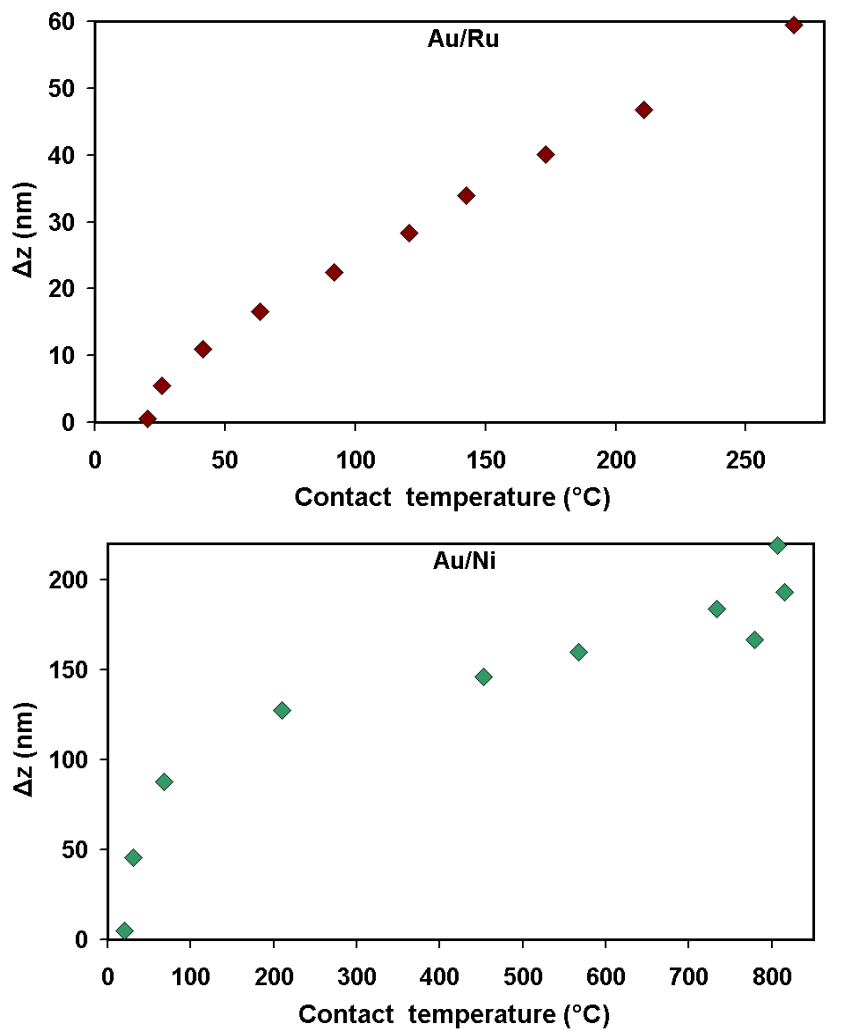

Figure 16: Location of the plane of maximum temperature in Au/Ru and Au/Ni contacts as a function of the maximum temperature

Figure 17 is a summary of the evolution of the contact topography previously described, depending on the contact temperature and the contact configuration (symmetric or asymmetric). The contact areas of case 2 and 3 are very similar whereas the contact area of case 4 is largely higher.

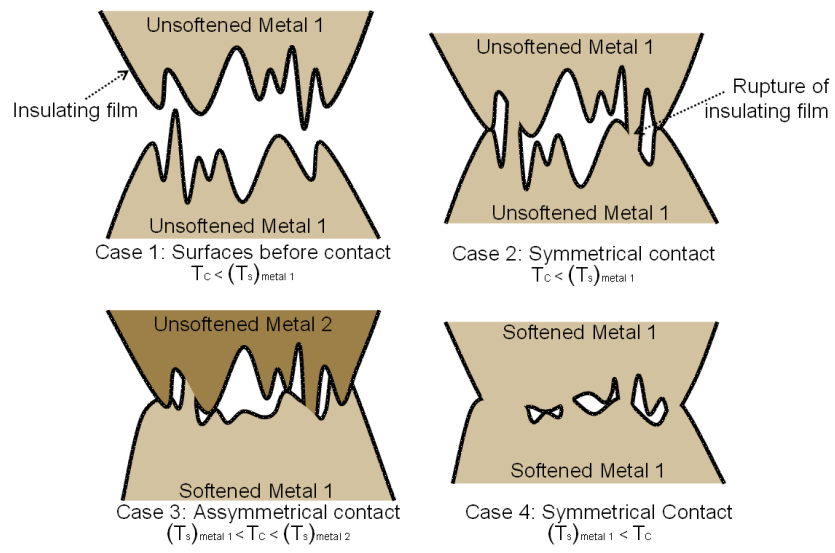

Figure 17: Schematic cross-sectional view of a micro-contact interface for 4 different cases.

The softening of the contact asperities offers cracks of the insulating film with the formation of new metallic spots between both contact members (case 4 on Figure 17). An increased adherence is generated by the increased contact surface for monometallic contacts. Hence this confirms that the contact junctions of asymmetric contacts are more stable and 
robust since the softening temperature is theoretically not reached at the contact interface for the given currents range.

\section{CONCLUSION}

This test facility enables new characterization tests of MEMS ohmic contacts under realistic conditions. The contact behavior represent a challenging multiphysic problem including mechanical, electrical and thermal interactions at micro-scale interfaces. Contact temperature, adhesion and thermo mechanical deformations of the contact asperities are significant factors in contact reliability. An emphasis was placed on the role of the low- to medium-power range leading to contact heating. First, the electro-mechanical responses of different contact configurations have been investigated. $\mathrm{Au} / \mathrm{Au}$ and $\mathrm{Au} / \mathrm{Ru}$ contacts have good performances and enhanced power-handling capability because of the electromechanical properties of the contact configuration. As a general rule, bimetallic contact should be able to handle relatively larger power thanks to the electro thermal properties of this specific contact configuration. The variation of the contact resistance is indeed determined by a competition between asperities flattening, which lowers the contact resistance, and heating, which can affect the topography of the contact surface by the activation of thermal failure mechanisms. Secondly, as a result, the measured data of $\mathrm{Rh} / \mathrm{Rh}$ contact provides solid and convincing proof that rhodium contact softening takes place at about $360^{\circ} \mathrm{C}$. In addition, it has been demonstrated that bimetallic contacts reduce adherence during the unloading phase alleviating or reducing the common failure mechanism of stuck contacts. On this regard, $\mathrm{Au} / \mathrm{Ru}$ contact seems to be a promising candidate for MEMS switches.

Finally, these tests highlight the convenience of this methodology for characterizing micro-contact reliability and performance under several test conditions. The knowledge and the understanding gathered by means of these experiments allows to shed some light on the contact physics. This enables the definition of additional recommendations for further improvements of micro-contact reliability.

\section{ACKNOWLEDGMENT}

This work was supported by the ANR (Agence Nationale de la Recherche) and EURIMUS respectively in the framework of the FAME and SMARTIS projects.

\section{REFERENCES}

[1] Rebeiz, GM and Muldavin, JB , "RF MEMS switches and switch circuits", IEEE Microwave magazine, vol. 2, no. 4, pp. 59--71, 2001

[2] Kataoka, K., Itoh, T., Suga, T. and Inoue, K., "Contact properties of $\mathrm{Ni}$ micro-springs for MEMS probe card", Proceedings of the 50th IEEE Holm Conference on Electrical Contacts, pp. 231-235, 2004

[3] Pruitt, BL, Park, W.T. and Kenny, TW, "Measurement system for low force and small displacement contacts", Journal of Microelectromechanical Systems, vol. 13, no. 2, pp. 220-229, 2004

[4] Wang, F., Li, X. and Feng, S., "Micro-cantilever probe cards with silicon and nickel composite micromachining technique for wafer-level burn-in testing", IEEE Transactions on Advanced Packaging, vol. 32, no. 2, pp. 468-477, 2009

[5] F. Solazzi, et al., "Contact Modelling of RF MEMS Switches Based On FEM Simulations", Proceedings of the $10^{\text {th }}$ International Symposium on RF MEMS and RF Microsystems, pp 173-176, July 2009
[6] Fortini, A., Mendelev, M.I., Buldyrev, S. and Srolovitz, D., "Asperity contacts at the nanoscale : Comparison of Ru and Au", Journal of Applied Physics, vol. 104, no. 7, pp 074320.1-074320.8, 2008

[7] Gilbert, K.W., Mall, S., Leedy, K.D. and Crawford, B., "A Nanoindenter Based Method for Studying MEMS Contact Switch Microcontacts", Proceedings of the 54th IEEE Holm Conference on Electrical Contacts, pp $137-144,2008$

[8] Kwon, H., Jang, S.S., Park, Y.H., Kim, T.S., Kim, Y.D., Nam, H.J. and Joo, Y.C., "Investigation of the electrical contact behaviours in Au-to-Au thin-film contacts for RF MEMS switches", Journal of Micromechanics and Microengineering no. 18, pp 1-9, 2008

[9] Yang, Z., Lichtenwalner, D., Morris, A., Menzel, S., Nauenheim, C., Gruverman, A., Krim, J. and Kingon, AI., "A new test facility for efficient evaluation of MEMS contact materials", Journal of Micromechanics and Microengineering no. 17, pp 1788-1795, 2007

[10] Broue, A., Dhennin, J., Courtade, F., Dieppedale, C., Pons, P., Lafontan, X. and Plana, R., "Characterization of $A u / A u, A u / R u$ and $R u / R u$ ohmic contacts in MEMS switches improved by a novel methodology", Proceedings of SPIE, Vo. 7592, pp. 75920A, 2010

[11] Broue, A. , Dhennin, J., Courtade, F., Charvet, PL., Pons, P., Lafontan, X. and Plana, $\mathrm{R}$ "Thermal and topological characterization of $A u, R u$ and $A u / R u$ based MEMS contacts using nanoindenter", Proceedings of IEEE MEMS 2010, pp. 544-547, 2010

[12] R. Holm, "Electrical Contacts-Theory and Applications", 4th ed. Berlin Germany: Springer-Verlag, 1967

[13] Brown, C. and Rezvanian, O. and Zikry, MA and Krim, J., "Temperature dependence of asperity contact and contact resistance in gold RF MEMS switches", Journal of Micromechanics and Microengineering, Vol. 19, pp. 025006, 2009

[14] Jensen, B.D. and Chow, LL and Huang, K. and Saitou, K. and Volakis, J.L. and Kurabayashi, K., "Effect of nanoscale heating on electrical transport in RF MEMS switch contacts," in Journal of Microelectromechanical Systems, vol. 14, no. 5, pp. 935-946, 2005.

[15] Broue, A., Dhennin, J., Courtade, F., Charvet, PL., Pons, P., Lafontan, X. and Plana, R.., "Validation of bending test by nanoindentation for micro-contact analysis of RF-MEMS switches", Proceedings of the $20^{\text {th }}$ MicroMechanics Europe workshop, pp. 318-321, September 2009

[16] Patton, ST and Zabinski, JS., "Fundamental studies of Au contacts in MEMS RF switches," in Tribology Letters, VOL. 18, pp 215-230, 2005.

[17] Feixiang Ke, Jianmin Miao and Oberhammer, J., "A ruthenium-based multimetal contact RF MEMS switch with a corrugated diaphragm”, IEEE/ASME Journal of Electromechanical Systems, vol. 17, no. 6, pp. 1447-1459, 2008.

[18] McGruer, NE and Adams, GG and Chen, L. and Guo, ZJ and Du, Y., "Mechanical, thermal, and material influences on ohmic-contact-type MEMS switch operation", 19th IEEE International Conference on Micro Electro Mechanical Systems, 2006. MEMS 2006 Istanbul, pp. 230-233, 2006

[19] David R. Lide, CRC Handbook of Chemistry and Physics, CRC Press Inc, 2009, 90e éd., Relié, 2804 p. (ISBN 978-1-420-09084-0)

[20] Ma, Q. and Tran, Q. and Chou, T.K.A. and Heck, J. and Bar, H. and Kant, R. and Rao, V., "Metal contact reliability of RF MEMS switches", Reliability, Packaging, Testing, and Characterization of MEMS/MOEMS VI, Proceedings of the SPIE, vol.6463, pp. 646305-646305, 2007

[21] Schimkat, J., "Contact materials for microrelays", The Eleventh Annual International Workshop on Micro Electro Mechanical Systems, MEMS 98 Proceedings, pp. 190-194, 1998

[22] Tomomi Umemoto, et al., "The Behavior of Surface Oxide Film on Ruthenium and Rhodium Plated Contacts", IEEE Transactions on Components, Hybrids, and Manufactured Technology, vol. CHMT-1, n 1 , March 1978

[23] Slade, P.G., "Electrical contacts: Principles and applications", 1999

[24] Stachowiak, G.W. and Batchelor, A.W. and Stachowiak, GW, "Engineering tribology", 2001 